\title{
THE EFFECTS OF SOLUTION TREATMENT ON THE MICROSTRUCTURE OF THE CAST NI-BASED IN100 SUPERALLOY
}

\author{
A. Jafari ${ }^{l}$, S. M. Abbasi ${ }^{l}$, A. Rahimi ${ }^{2}$, M. Morakabati ${ }^{l}$, M. Seifollahi ${ }^{l}$ \\ ${ }^{I}$ Metallic Materials Research Center (MMRC), Malek-Ashtar University of \\ Technology, Tehran, Iran \\ ${ }^{2}$ Department of Materials Science and Engineering, Iran University of Science \\ and Technology (IUST), Teharn, Iran
}

Received 10.05.2015

Accepted 13.07.2015

\begin{abstract}
In this research, the effects of the partial, full and partial + full solution heat treatments followed by aging at $900{ }^{\circ} \mathrm{C}$ for $10 \mathrm{~h}$, on the microstructure of cast Ni-based IN100 superalloy were assessed. It has been found that, the alloy in the partial + full solution treated condition had the optimal combination of $\gamma^{\prime}$ morphology, volume fraction and size. In this condition, the alloy possesses a cubic primary $\gamma^{\prime}$ with an average size of $470 \pm 10 \mathrm{~nm}$ and $45 \%$ volume fraction. Discrete $\mathrm{M}_{23} \mathrm{C}_{6}$ and $\mathrm{M}_{6} \mathrm{C}$ carbides were formed at the grain boundaries and the morphology of the cubic MC carbide was changed to the spherical shape. In addition, the volume fraction of $\gamma^{\prime} / \gamma$ eutectic phase dropped to half of its value, compared to the as-cast alloy. During partial solution treatment followed by aging, discrete carbides were formed at the grain boundaries. This treatment without full solutioning was not an effective method to provide an optimal volume fraction and arrangement of $\gamma^{\prime}$ and MC carbides morphology. Full solutioning alone, changed the cubic morphology of the primary $\gamma^{\prime}$ and the blocky MC carbides to the spherical shape. Key words: Ni-based IN100 superalloy; Solution treatment; Primary $\gamma^{\prime}$; Secondary $\gamma^{\prime}$; Carbides.
\end{abstract}

\section{Introduction}

IN100 is a nickel-based superalloy widely used in the gas turbine industry such as blades and nozzles. This alloy is also a perfect candidate material for high temperature forging dies due to its outstanding high temperature tensile and rupture strength [1-3]. The microstructure of the alloy consists of L12 type $\gamma^{\prime}$ phase [(Ni3(Ti,

\footnotetext{
*Corresponding author: Ahmad Rahimi, ahmadrahimi1367@gmail.com
} 
Al)] with a trimodal size distribution in a FCC $\gamma$ matrix. The trimodal $\gamma^{\prime}$ distribution includes: primary $\gamma^{\prime}(\sim 450 \mathrm{~nm})$, secondary $\gamma^{\prime}(\sim 15$ to $30 \mathrm{~nm})$ and tertiary $\gamma^{\prime}(<15 \mathrm{~nm})$. It has been reported that [4] the IN100 alloy with about 60 pct. volume fraction of $\gamma^{\prime}$, shows the excellent microstructural stability and mechanical properties at moderately high temperature.

Minor phases such as carbide and $\gamma^{\prime} / \gamma$ eutectic have also been identified in the alloy and may be detrimental to mechanical properties. Carbides of type (Ti, Mo)C, (Ni, $\mathrm{Co}, \mathrm{Mo}, \mathrm{Ti}_{6} \mathrm{C}$ and $\mathrm{Cr}_{23} \mathrm{C}_{6}$ are also detected in Ni-based superalloys. Blocky Ti-rich MC carbides are formed during solidification and distributed into the $\gamma$ matrix between the dendritic cells and at the grain boundaries [5]. MC carbides have an incoherent interface to the matrix and are blocky, so they often act as crack initiation sites. $\mathrm{M}_{6} \mathrm{C}$ and $\mathrm{M}_{23} \mathrm{C}_{6}$ carbides usually precipitate at the grain boundaries. These carbides with proper size and morphology impede grain boundary sliding (GBS) and cause improvement in the high temperature strength of the alloy [6].

The amount and the size of $\gamma^{\prime} / \gamma$ eutectic phase formed during solidification depends on the solidification rate and the alloy composition [7]. This phase has a negative effect on the creep behavior especially on the second and the third region consequently decreasing the alloy lifetime [8].

Casting and heat treatment processes play an important role in determining the microstructure of the superalloy. A suitable solution and aging heat treatment can improve the mechanical properties of IN100 alloy through the following events: increasing the $\gamma^{\prime}$ volume fraction and optimizing its morphology, the modification of $\mathrm{MC}$ carbides morphology, the precipitation of $\mathrm{M}_{6} \mathrm{C}$ and $\mathrm{M}_{23} \mathrm{C}_{6}$ carbides, and reducing solidification segregations and $\gamma^{\prime} / \gamma$ eutectic phase [9]. Various studies $[4,8,10]$ have been conducted to modify the microstructure of IN100 applying vacuum induction melting (VIM) and cast into metallic and ceramic molds through optimizing the alloying elements, solidification parameters, various heat treatment cycles, etc. However to the best of author's knowledge, the influence of different kind of solution cycle on the microstructure of the IN100 alloy prepared via different processes such as VIM, electro-slag remelting (ESR) and vacuum-arc remelting (VAR), has not been investigated systematically, so far. Thus, in the present work, the microstructure of the alloy, including $\gamma^{\prime}$ phases, carbides and $\gamma^{\prime} / \gamma$ eutectic phase, is evaluated after various solution treatment cycles.

\section{Experimental procedure}

An IN100 Ni-based superalloy was melted in a VIM furnace and cast into cylindrical bars with a diameter of $60 \mathrm{~mm}$ and a length of $50 \mathrm{~mm}$. The furnace was evacuated to 10-3 mbar and purged with high purity argon. All raw materials were rinsed separately with acetone and charged into a metallic crucible. The reactive elements were charged after full melting of the charged material. The pouring temperature was $1450^{\circ} \mathrm{C}$.

The alloy was remelted in an ESR furnace to improve homogeneity and reduce impurities such as sulphur and inclusions. The remelted slag composition was $60 \% \mathrm{CaF} 2-20 \% \mathrm{Al} 2 \mathrm{O} 3-20 \% \mathrm{CaO}$ (wt.\%). Finally, the ESR ingot was remelted in the VAR furnace and cast into the cylindrical bars with $100 \mathrm{~mm}$ diameter and $90 \mathrm{~mm}$ length. Chemical composition of the alloy after remelting, determined using emission spectrometer quantometer is listed in Table $1.15 \times 15 \times 15 \mathrm{~mm}$ specimens were exposed 
to different solution annealing cycles, air-cooled (AC) followed by aging. The solution heat treatments are designed to dissolve $\gamma^{\prime} / \gamma$ eutectic, $\gamma^{\prime}$ and carbide phases and allow the optimum reprecipitation of these phases upon cooling or after ageing.

Table1. Chemical composition of the IN100 (wt.\%).

\begin{tabular}{|l|l|l|l|l|l|l|l|}
\hline $\mathrm{Ni}$ & $\mathrm{Al}$ & $\mathrm{Ti}$ & $\mathrm{Cr}$ & $\mathrm{Co}$ & $\mathrm{Mo}$ & $\mathrm{C}$ & $\mathrm{V}$ \\
\hline Bal. & 5.23 & 4.41 & 9.82 & 15.07 & 3.01 & 0.18 & 1.02 \\
\hline
\end{tabular}

According to Table 2, four different heat treatment cycles including aging (A)[11], partial (B)[12], full (C)[4], and partial + full (D)[13] solution treatments followed by aging at $900{ }^{\circ} \mathrm{C}$ for $10 \mathrm{~h}$ were applied to the as-cast alloy.

Table2. Different heat treatment cycles applied on the specimens.

\begin{tabular}{|l|l|l|}
\hline Heat treatment cycle & Solution treatment & Aging treatment \\
\hline A & -- & $900{ }^{\circ} \mathrm{C} / 10 \mathrm{~h}$ \\
\hline B & $1080{ }^{\circ} \mathrm{C} / 4 \mathrm{~h} / \mathrm{AC}$ & $900{ }^{\circ} \mathrm{C} / 10 \mathrm{~h}$ \\
\hline $\mathrm{C}$ & $1210^{\circ} \mathrm{C} / 2 \mathrm{~h} / \mathrm{AC}$ & $900{ }^{\circ} \mathrm{C} / 10 \mathrm{~h}$ \\
\hline $\mathrm{D}$ & $1210^{\circ} \mathrm{C} / 2 \mathrm{~h} / \mathrm{AC}+1080^{\circ} \mathrm{C} / 4 \mathrm{~h} / \mathrm{AC}$ & $900{ }^{\circ} \mathrm{C} / 10 \mathrm{~h}$ \\
\hline
\end{tabular}

Metallographic sections were prepared using standard polishing procedures according to ASTM E3-01. The microstructure was revealed using $10 \mathrm{gr} \mathrm{Cu}_{2} \mathrm{~S}+50 \mathrm{ml}$ $\mathrm{HCl}+50 \mathrm{ml} \mathrm{H}_{2} \mathrm{O}$ solution. A XMU TESCAN scanning electron microscope (SEM) with an energy dispersive spectroscopy (EDS) analyzer operating at $15 \mathrm{KV}$ and Olympus optical microscope (OM) were used to analyze the morphology and distribution of the phases. The size and the volume fraction of the phases were calculated using Image Analyzer software according to ASTM-E112 and ASTM-E562. The segregation behavior of the elements was analyzed using EDS line scan across the phases as well as the matrix. Also, X-ray diffraction (XRD) analysis with $\mathrm{Cu}-\mathrm{K} \alpha$ radiation at $40 \mathrm{kV}$ and $30 \mathrm{~mA}$ was employed for phase identification. The curve were recorded at the lowest scanning rate and $2 \theta$ scan range to better monitor the $\gamma^{\prime}$ and $\gamma^{\prime} / \gamma$ eutectic phases.

\section{Results and discussion \\ As-cast microstructure}

Fig. 1 shows the OM and SEM micrograph of the as-cast IN100 alloy. The ascast specimen exhibits a two-phase $\gamma$ and $\gamma^{\prime}$ microstructure with a dendritic segregation pattern and a limited amount of $\gamma^{\prime} / \gamma$ eutectic phase in some inter-dendritic regions (Fig. 1a-c). Secondary precipitation of finer $\gamma^{\prime}$ occurs in the small region of the matrix channels (Fig. 1d). The secondary $\gamma^{\prime}$ volume fraction in the as-cast condition was measured to be $10 \pm 1 \%$ with an average size of $17 \pm 5 \mathrm{~nm}$. The SEM micrograph and the EDS analysis of the carbide in the cast alloy are shown in Fig. 1e. The EDS result confirmed that this phase is $(\mathrm{Ti}, \mathrm{Mo}) \mathrm{C}$. No other carbide of any type was detected in the as-cast microstructure.

As it is seen in Fig. 1b, the cubic or rounded primary $\gamma^{\prime}$ precipitates aligned randomaly with an average size of $420 \pm 20 \mathrm{~nm}$ and a volume fraction of $25 \pm 3 \%$. The channels of $\gamma$ matrix are not clear and homogeneous, but they follow pretty zigzag shape. As it is known, in nickel-based superalloys, typical dendritic structure is formed 
during non-equilibrium and rapid solidification [14]. As a result of non-equilibrium solidification, the primary $\gamma^{\prime}$ with suitable morphology is not formed. According to the literature [4], the best mechanical properties of this alloy is achieved by $60 \%$ volume fraction of ordered cubic $\gamma^{\prime}$. Hence, further processes such as heat treatment is required to optimize the morphology and volume fraction of $\gamma^{\prime}$.
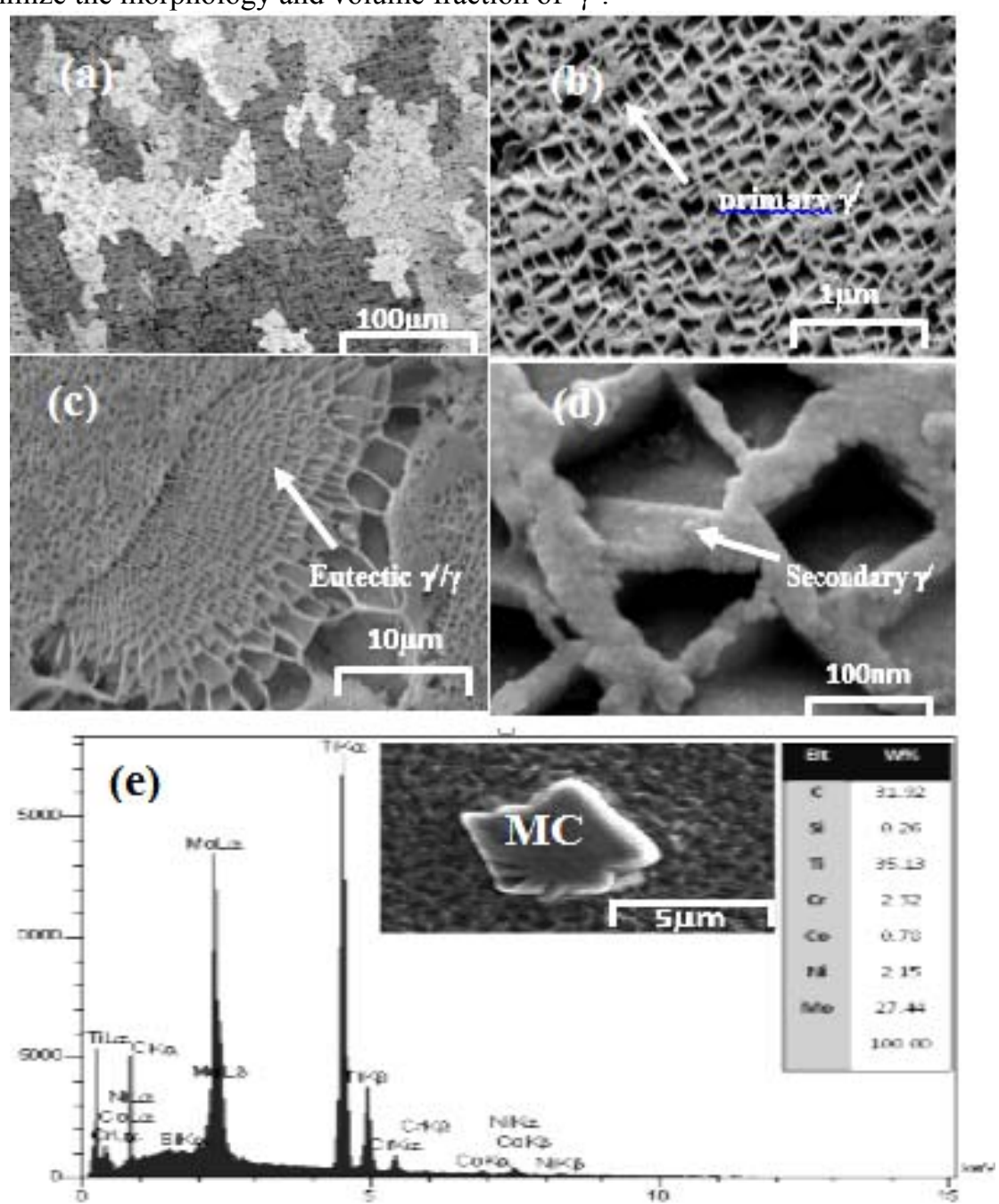

Fig.1. OM and SEM micrographs of the as-cast IN100 alloy. (a) dendritic segregation pattern; (b) primary $\gamma^{\prime}$ into the matrix $\gamma$; (c) $\gamma^{\prime} / \gamma$ eutectic; (d) secondary $\gamma^{\prime}$ and (e) EDS result of MC carbide.

It can also be noted that the boundaries of austenitic grains with an average size of $235 \pm 10 \mu \mathrm{m}$ appeared in serrated shape. The grain boundary serrations are developed as a result of grain boundary impingement by growing secondary $\gamma^{\prime}$ phases or carbides. 
The results of the line scan technique to determine the composition of $\gamma^{\prime} / \gamma$ eutectic is shown in Fig. 2. In comparison to the bulk alloy composition, the $\gamma^{\prime} / \gamma$ eutectic phase is significantly enriched in $\mathrm{Ti}$ and $\mathrm{Al}$ and depleted in $\mathrm{Cr}$ and $\mathrm{Co}$. As the estimated partition coefficient of $\mathrm{Al}$, and $\mathrm{Ti}$ is less than unity [15], they are segregated into the inter-dendritic regions and solidified at the last stage of solidification in the form of eutectic. The volume fraction of $\gamma^{\prime} / \gamma$ eutectic phase in the cast alloy is about $4 \pm 1 \%$. The $\gamma^{\prime} / \gamma$ eutectic phase has a low melting point. Therefore, it should be eliminated during heat treatment in order to preserve the high temperature strength of the alloy [16].
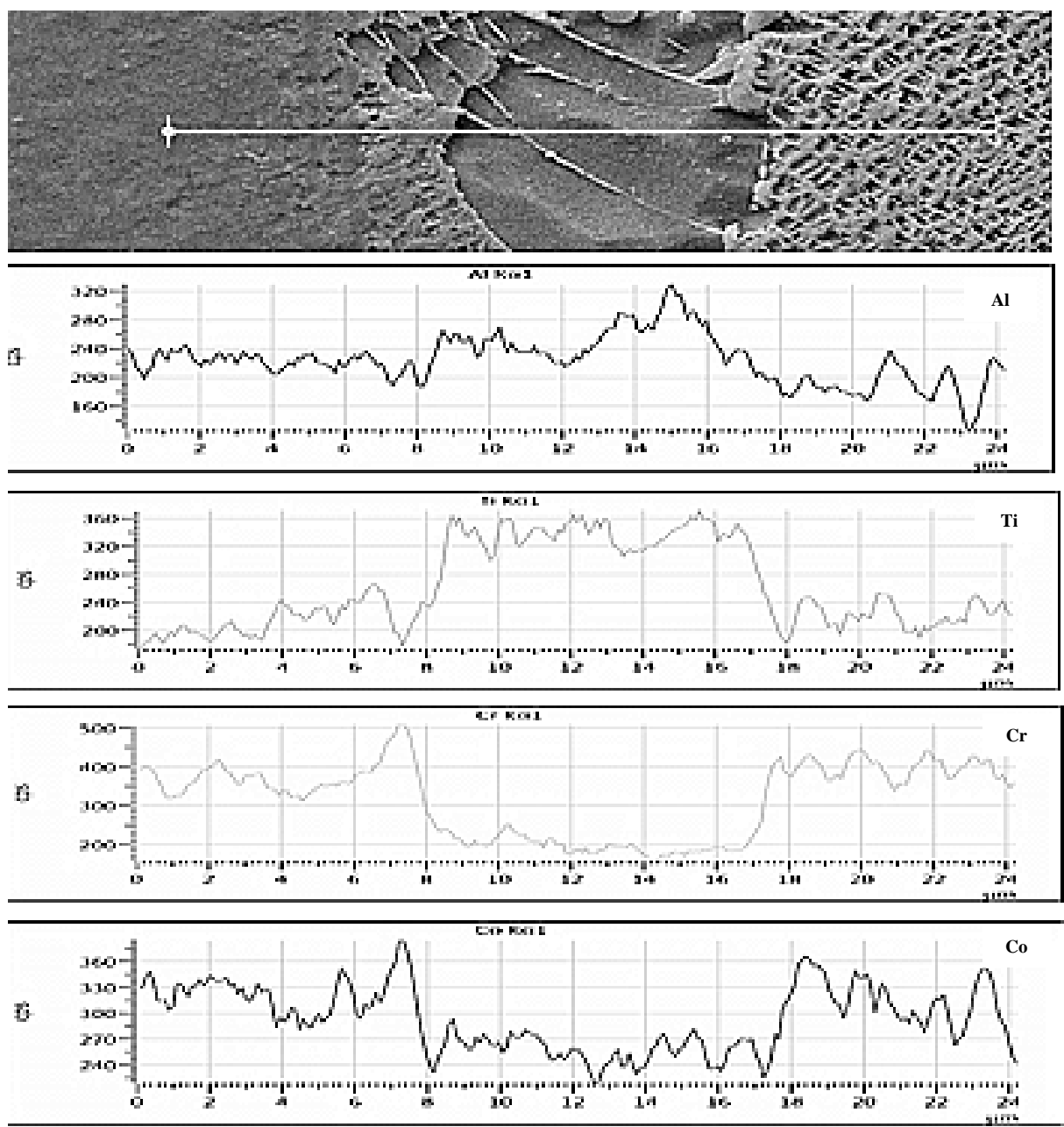

Fig.2.The EDS line scan across the eutectic $\gamma^{\prime} / \gamma$ phase.

\section{The effect of heat treatment on the dendritic structure and the $\gamma^{\prime} / \gamma$ eutectic phase}

The microstructure of the IN100 alloy heat treated with A and B cycles shows dendritic structure (Fig. 3a, b). As it may be seen, homogenization has not been 
accomplished. Hence, it can be deduced that the solution temperature and time in A and B cycles were too low to reduce the segregation. During A and B cycles the grain size of specimen increases up to $242 \pm 8$ and $267 \pm 7 \mu \mathrm{m}$, respectively, which is attributed to the acceleration of diffusion and grain boundary sliding. Fig. 3c, d shows the OM microstructures of the alloy heat treated with $\mathrm{C}$ and $\mathrm{D}$ cycles, respectively. The solution temperature of $\mathrm{C}$ cycle was $130{ }^{\circ} \mathrm{C}$ higher than that of $\mathrm{B}$ one. As it is seen, it is difficult to distinguish the dendritic segregation pattern. The average grain size of $\gamma$ in these specimens is $290 \pm 5 \mu \mathrm{m}$ and $295 \pm 8 \mu \mathrm{m}$, for C and D cycles, respectively. It has been reported [10] that during solution treatment of the cast Ni-based superalloys, MC carbides decompose to M23 6 and $\mathrm{M} 6 \mathrm{C}$ carbides at the grain boundaries leading to pin the grain boundaries and inhibit further grain growth. The similar grain size in the specimens treated with $\mathrm{C}$ and $\mathrm{D}$ cycles can be attributed to the formation of $\mathrm{MC}$ carbides. Hence, two step annealing cannot affect the grain growth considerably.

Fig. 4a, b shows the SEM micrograph of $\gamma^{\prime} / \gamma$ eutectic of heat treated specimens through B and C cycles, respectively. Accordingly, $\gamma^{\prime} / \gamma$ eutectic has not been dissolved yet. This can be due to insufficient temperature and/or time to reach the complete solutioning of the $\gamma^{\prime} / \gamma$ eutectic. However, the solution temperature should be sufficiently below the solidus temperature to avoid incipient melting of grain boundaries. It is interesting to note that the amount of this phase decreased to $3 \pm 1 \%$ in both specimens treated with B and C cycles. Partial + full annealing treatment is an effective method to solution $\gamma^{\prime} / \gamma$ eutectic completely. The $\gamma^{\prime} / \gamma$ eutectic volume fraction of the specimen going through the D cycle was reduced to $2 \pm 1 \%$. The $\gamma^{\prime} / \gamma$ eutectic volume fraction of the specimens heat treated with different cycles listed in Table 3, supports the above results.

Table 3. The volume fraction of $\gamma^{\prime} / \gamma$ eutectic phase after heat treatment with different cycles.

\begin{tabular}{|l|l|}
\hline Sample & Volume fraction of $\gamma^{\prime} / \gamma$ eutectic (\%) \\
\hline Casting & $4 \pm 1$ \\
\hline B & $3 \pm 1$ \\
\hline C & $3 \pm 1$ \\
\hline D & $2 \pm 1$ \\
\hline
\end{tabular}



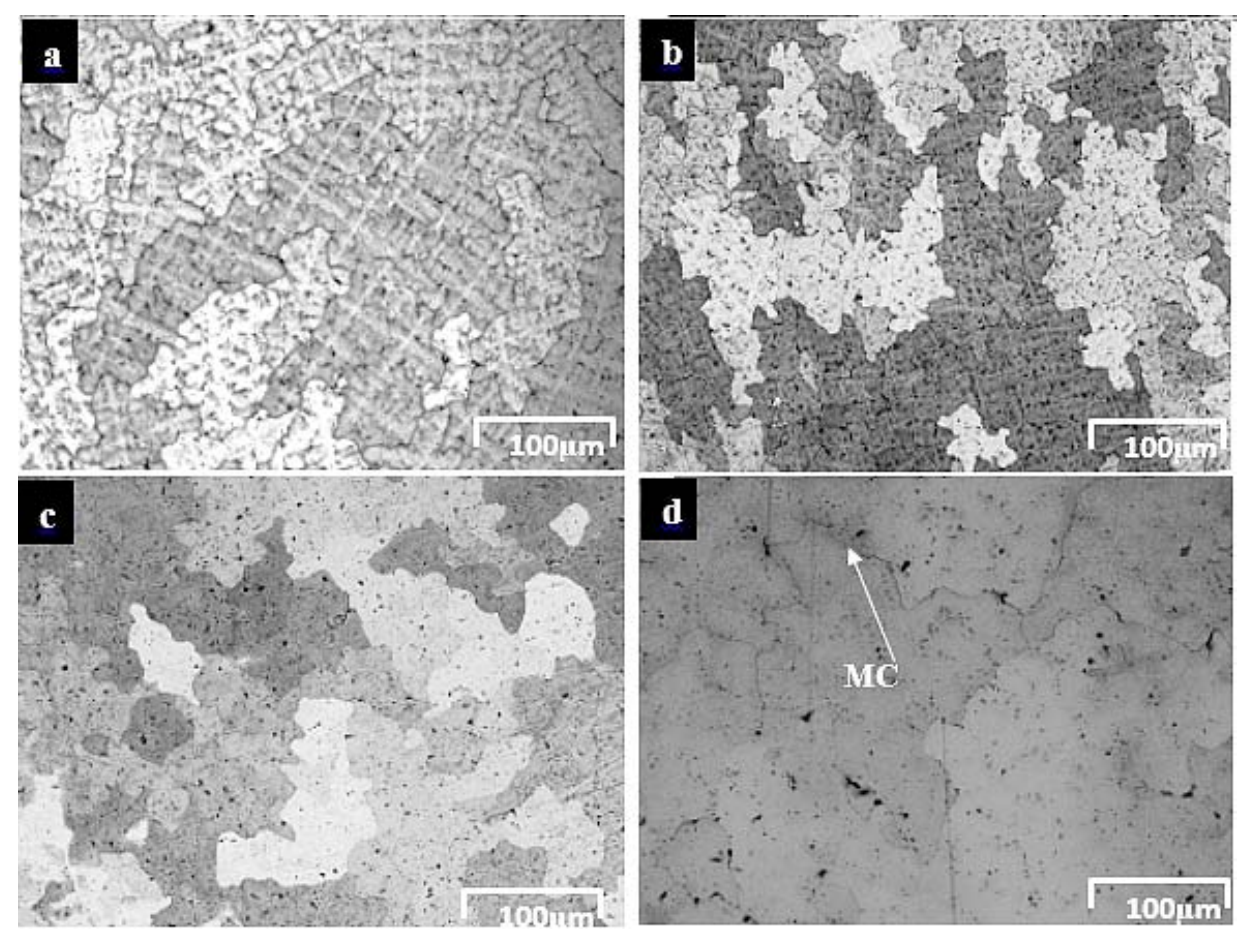

Fig.3.The microstructure of the IN100 alloy heat treated by: (a) A; (b) B; (c) C and (d) D cycle.
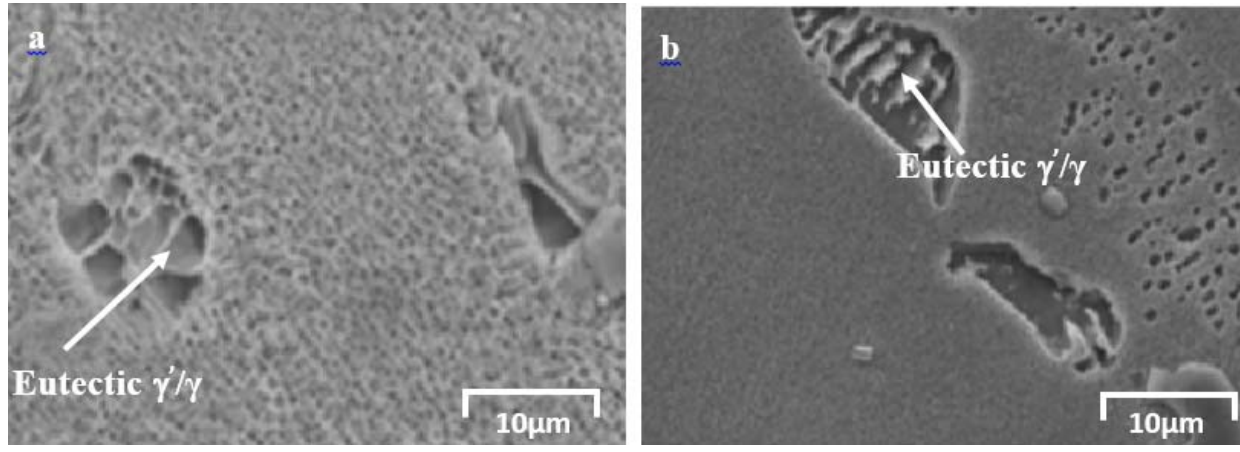

Fig.4. SEM micrograph of the specimen heat treated with (a) B and (b) C cycles showing $\gamma^{\prime} / \gamma$ eutectic.

The XRD patterns of the as-cast sample as well as the heat treated sample subjected to D cycle are shown in Fig. 5. The XRD pattern of the as-cast alloy reveals the presence of $\gamma^{\prime}$ phase and $\gamma^{\prime} / \gamma$ eutectic, whereas only $\gamma^{\prime}$ is found in the latter one. It should be noted that the $2 \theta$ scan range was in the region where $\gamma$ matrix is not present. The $\gamma^{\prime} / \gamma$ eutectic volume fraction of the alloy heat treated with $\mathrm{D}$ cycle is quite low to be detected by XRD. In addition, the peak intensity of $\gamma^{\prime}$ in the heat treated alloy is higher than that of the as-cast one. This indicates that partial + full annealing treatment 
causes volume fraction of $\gamma^{\prime}$ to precipitate after aging reducing the chemical inhomogeneity and segregation of the as-cast specimen.
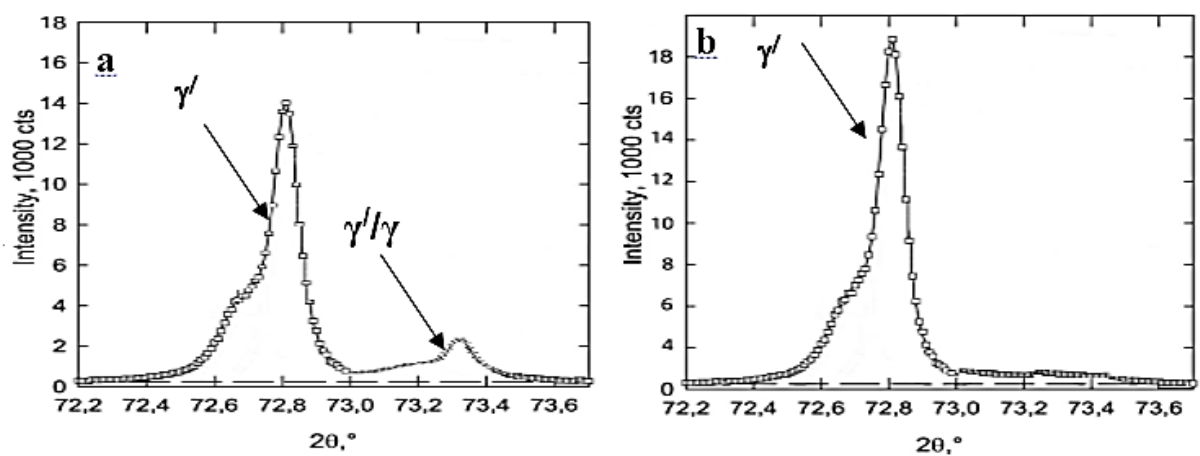

Fig.5.The XRD pattern of (a) the as-cast alloy and (b) the alloy heat treated with $D$ cycle.

\section{The effect of solution heat treatment on the primary $\gamma$ ' precipitates}

Fig. 6 shows the SEM micrographs of the alloy after different solution heat treatment cycles. The size and the volume fraction of the primary $\gamma^{\prime}$ of all specimens are measured and summarized in Fig. 7.

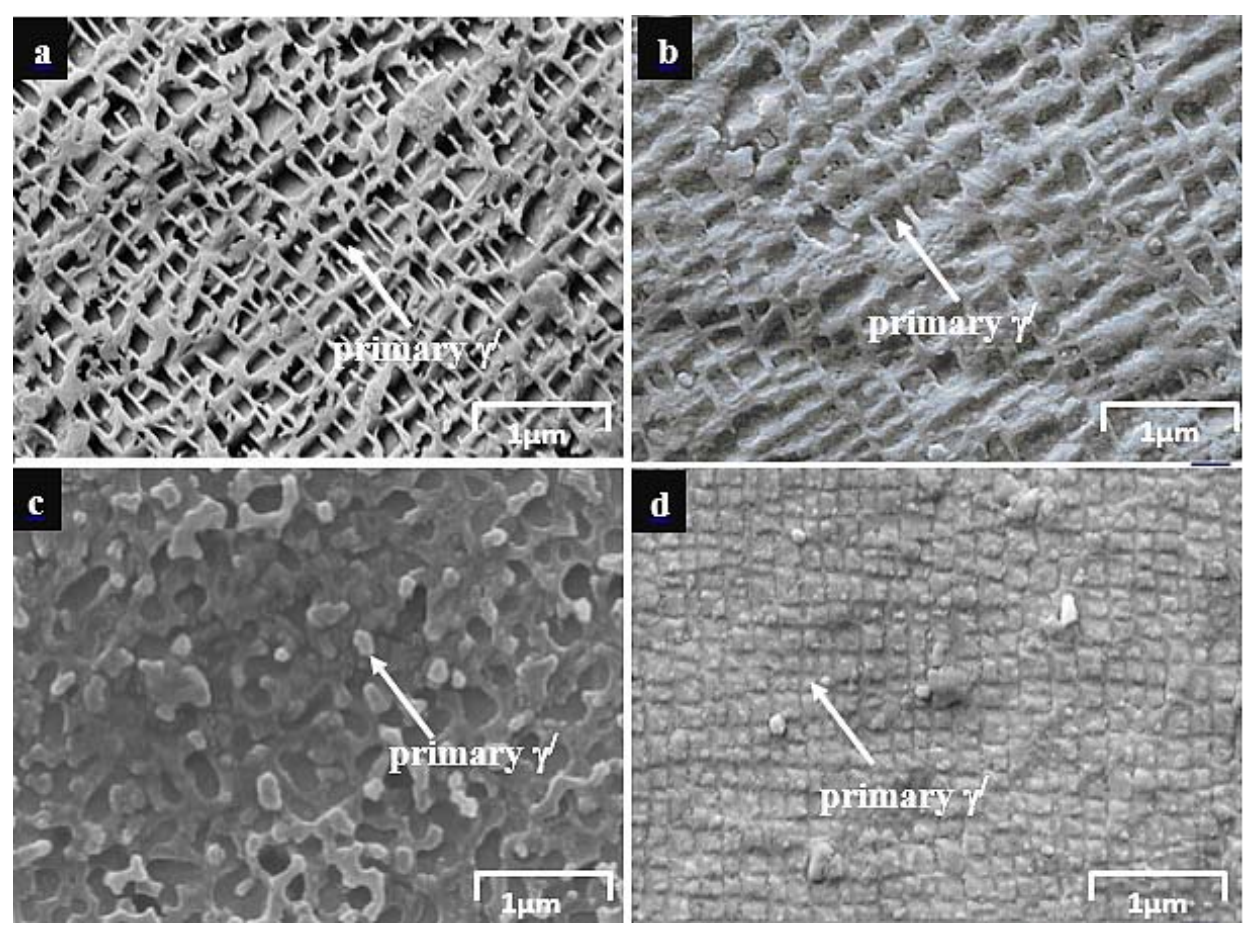

Fig.6. The SEM micrographs of the as-cast alloy with different heat treatment cycles. (a) aging; (b) partial annealing; (c) full annealing and (d) partial + full annealing. 
Comparison of the micrographs of Fig. 6a and Fig. 1b, shows that the primary $\gamma^{\prime}$ morphology remains unchanged by ageing. However, the size and the volume fraction of this phase increase slightly to $450 \pm 20 \mathrm{~nm}$ and $30 \pm 3 \%$, respectively. Aging alone of the supersaturated matrix of the as-cast alloy leads to further formation of the $\gamma^{\prime}$ phase and increase in the $\gamma^{\prime}$ volume fraction. Fig. $6 \mathrm{~b}$ shows the SEM micrograph of the specimen heat treated with B cycle (partial solution). Performing this cycle prior to aging leads the optimal properties of primary $\gamma^{\prime}$ as far as morphology, size and volume fraction are concerned [17]. The primary $\gamma^{\prime}$ size and volume fraction of the specimen heat treated with B cycle increase to $460 \pm 10 \mathrm{~nm}$ and $35 \pm 3 \%$, respectively, which is comparable to the as-cast alloy. It is notable that, after this heat treatment, the morphology of the primary $\gamma^{\prime}$ was slightly changed, but was not converted to the ideal ordered cubic shape. It seems that, due to the insufficient time and temperature for reducing segregation, the $\gamma^{\prime}$ volume fraction cannot be reached to its idealistic values.
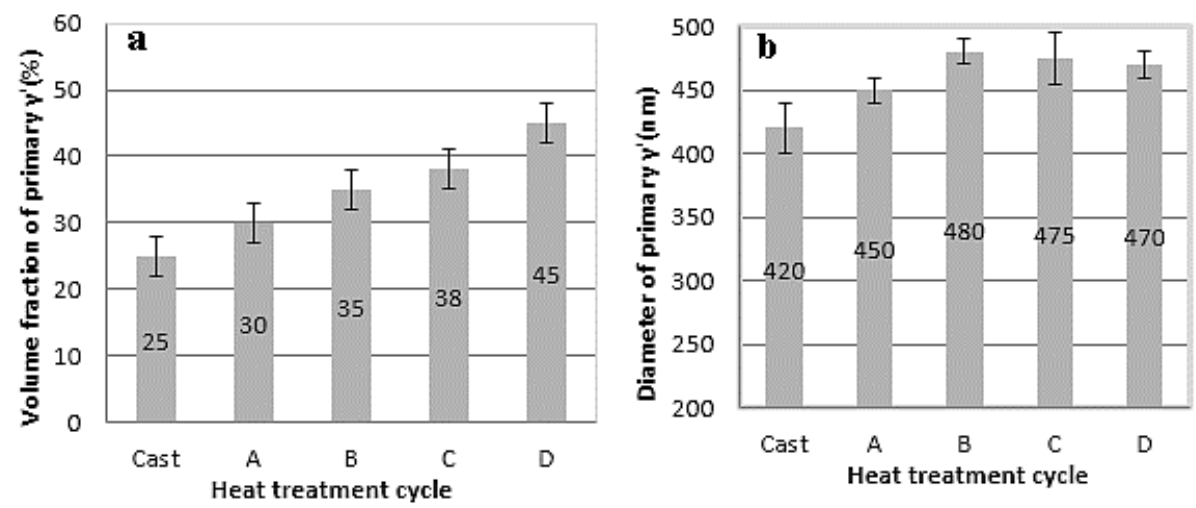

Fig.7. (a) The volume fraction and (b) the size of primary $\gamma$ ' of the IN100 alloy after different solution treatment.

It may be supposed that the primary $\gamma$ 'during heat treatment obeyed the LSW (Lifshitz-Slyozov-Wagner) theory which states $r^{3}-r_{o}{ }^{3}=k t$, where $r$ is the average size of the particle after aging time $(t), r_{o}$ is the initial average size, and $k$ is the growth rate constant. In order to evaluate the validation of LSW theory, the aging times of B cycle was extended to $25 \mathrm{~h}$. Then, the growth of the primary $\gamma$ 'precipitates after $0,2,3,5,10$, 15 , and $25 \mathrm{~h}$ was studied. The SEM microstructure of the specimens aged for $0,2,3$, and $25 \mathrm{~h}$ is shown in Fig. 8. According to Fig. 8a, the $\gamma^{\prime}$ phase was partially dissolved in solutionized specimens. During aging, the globular $\gamma^{\prime}$ phase changes to the near cubic morphology at short time and to the cubic morphology at long time. For each aging time, the $\gamma^{\prime}$ particle sizes were measured and their average sizes are listed in Table 4. The plot of $\gamma^{\prime}$ average diameter as a function of aging time gives liner curve with exponent of $1 / 3$ (Fig.9). This suggests that the growth of $\gamma^{\prime}$ precipitates in the alloy was accelerated, which can be determined by volume diffusion according to the Ostwald ripening mechanism:

$$
\mathrm{r}^{3}-\mathrm{r}_{\mathrm{o}}^{3}=\mathrm{kt}
$$


Where $r$ is the average size of the particle after aging time ( $t$ ), ro is the initial average size, and $\mathrm{k}$ is the growth rate constant.

The value of $\mathrm{k}$ determined as $0.00939 \mu \mathrm{m} / \mathrm{h}$ supports that the growth of the $\gamma^{\prime}$ phase obeys the LSW theory in spite of the poor linearity (R squared $<0.9$ ).

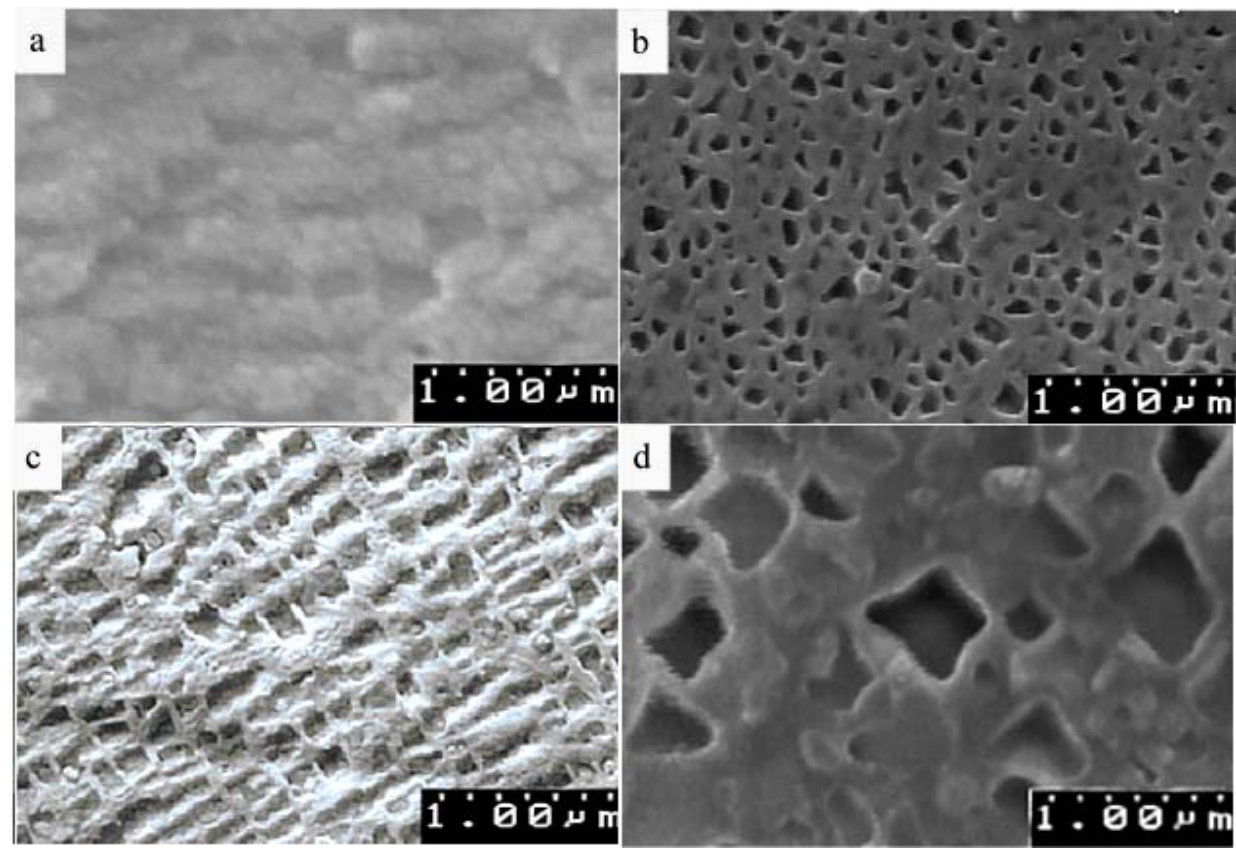

Fig.8. The SEM microstructure of specimens aged for, (a) 0; (b) 2; (c) 3 and (d) $25 \mathrm{~h}$.

Table 4. The r'particle sizes after different aging times.

\begin{tabular}{|l|l|}
\hline Aging time (hr.) & Particle size (nm) \\
\hline 0 & $320 \pm 20$ \\
\hline 2 & $360 \pm 18$ \\
\hline 3 & $390 \pm 19$ \\
\hline 5 & $415 \pm 21$ \\
\hline 10 & $480 \pm 23$ \\
\hline 15 & $530 \pm 20$ \\
\hline 25 & $590 \pm 19$ \\
\hline
\end{tabular}




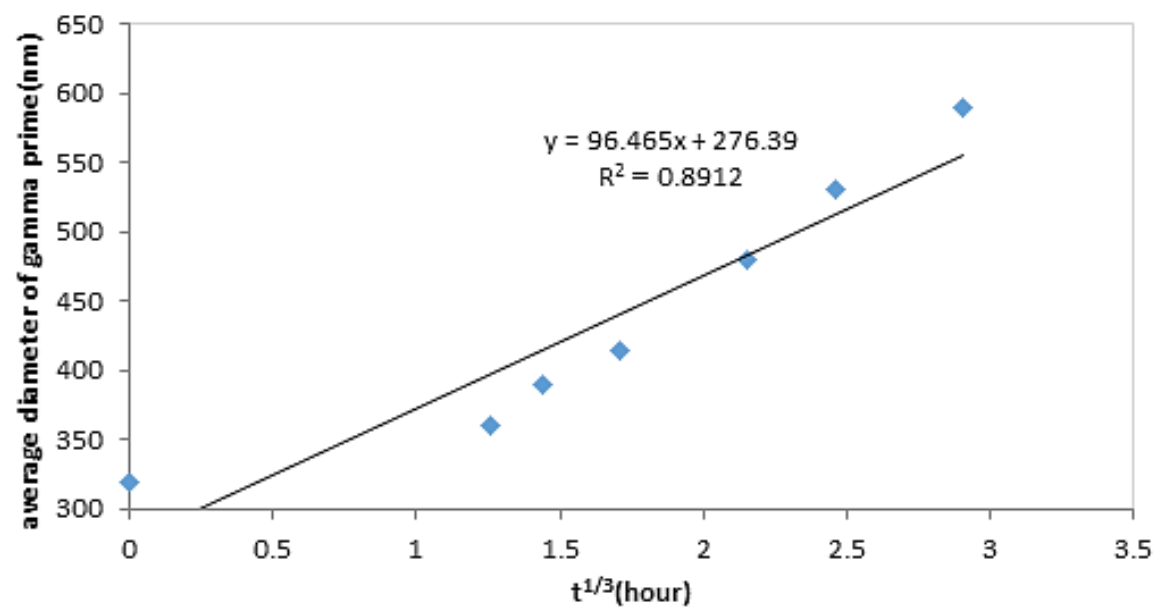

Fig.9. Variation of average diameter of $\gamma$ ' with aging time.

The SEM micrograph of the specimen heat treated according to $\mathrm{C}$ cycle is shown in Fig. 6 c. As can be seen, the morphology of the primary $\gamma^{\prime}$ was completely changed to spherical one with an average size of $475 \pm 20 \mathrm{~nm}$ and volume fraction of $38 \pm 3 \%$. Therefore, increase in the temperature results in the growth and coagulation of the $\gamma$ ' phase. It has been reported [18] that the decrease in interfacial energy between the precipitated phase and the matrix acts as the driving force for the growth of precipitates.

Fig. $6 \mathrm{~d}$ shows the microstructure of the alloy heat treated with $\mathrm{D}$ cycle. The primary $\gamma^{\prime}$ size is within the range of $470 \pm 10 \mathrm{~nm}$ occupying $45 \pm 3 \mathrm{vol} \%$ of the alloy. Comparing the microstructure of heat treated alloy (Fig. $6 \mathrm{~d}$ ) with the as-cast one (Fig. 1 b), shows the increase of $80 \%$ in the volume fraction and $50 \mathrm{~nm}$ in the size of the primary $\gamma^{\prime}$ in heat treated condition. It should be noted that the shape of the primary $\gamma^{\prime}$ is changed to the ordered cubic structure applying $\mathrm{D}$ cycle. This morphology proved to be the optimal for high temperature mechanical properties of this alloy [19].

\section{The effect of different heat treatment cycles on the secondary $\gamma$ ' particles}

The secondary $\gamma^{\prime}$ morphology of the heat treatment specimens is shown in Fig. 10 a-d. As can be seen, the secondary $\gamma^{\prime}$ morphology is spherical in all specimens and remains unchanged in comparison to the as-cast structure (see Fig. $1 \mathrm{~d}$ ). The formation mechanism of these particles can be correlated to the diffusion of alloying elements during aging. Previous studies [7] demonstrated that after rapid cooling from solution temperature, matrix supersaturation with solute elements such as Al and Ti is the main reason for precipitation of the secondary $\gamma^{\prime}$.

Fig. 11 shows the variation of the secondary $\gamma^{\prime}$ volume fraction and its size for all specimens. It can be noted that the volume fraction of the secondary $\gamma^{\prime}$ is independent of the heat treatment cycle, while its size is slightly influenced by heat treatment. During various heat treatments, an increase of $50 \%$ in the secondary $\gamma^{\prime}$ volume fraction can be seen. 

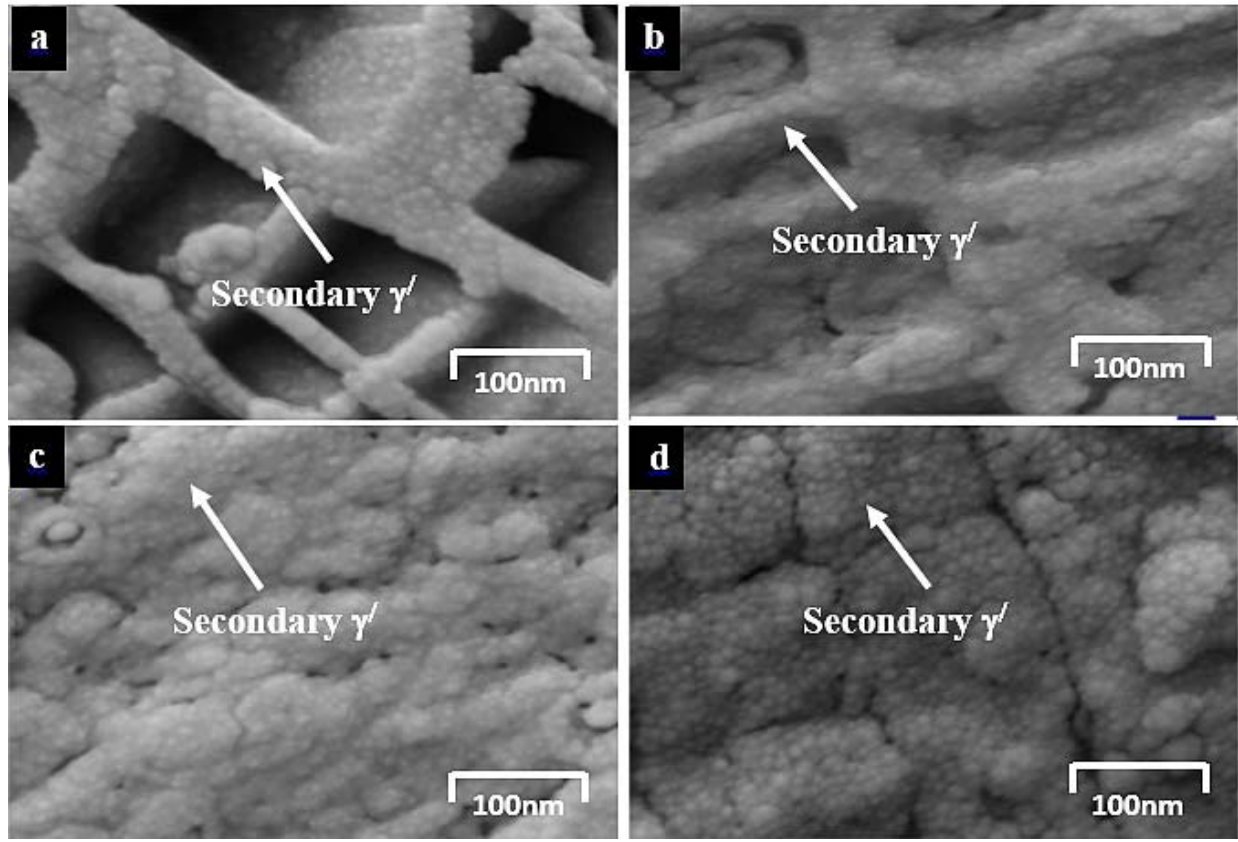

Fig.10. SEM images of the specimens after different heat treatment cycles: (a) aging; (b) partial annealing; (c) full annealing and (d) partial + full annealing.
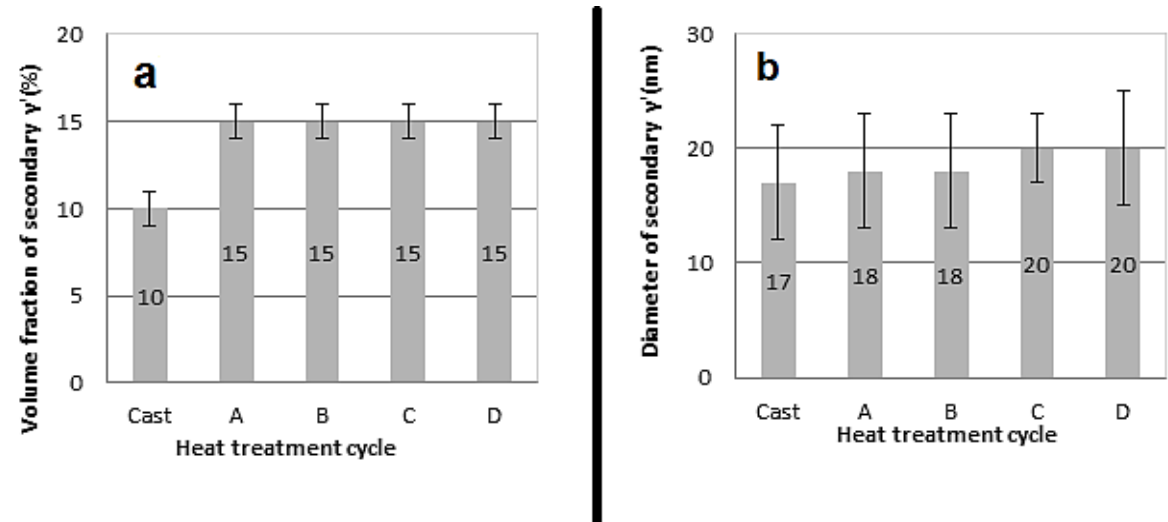

Fig.11. (a) The volume fraction and (b) the size of secondary $\gamma^{\prime}$ of the IN100 alloy after different solution treatment.

\section{The effect of different heat treatment cycles on the carbides}

SEM micrographs of the carbides in the heat treated specimens are shown in Fig. 12. As mentioned in section 3.1, MC was the only carbide present in the microstructure of as-cast specimen (see Fig. 1e). 

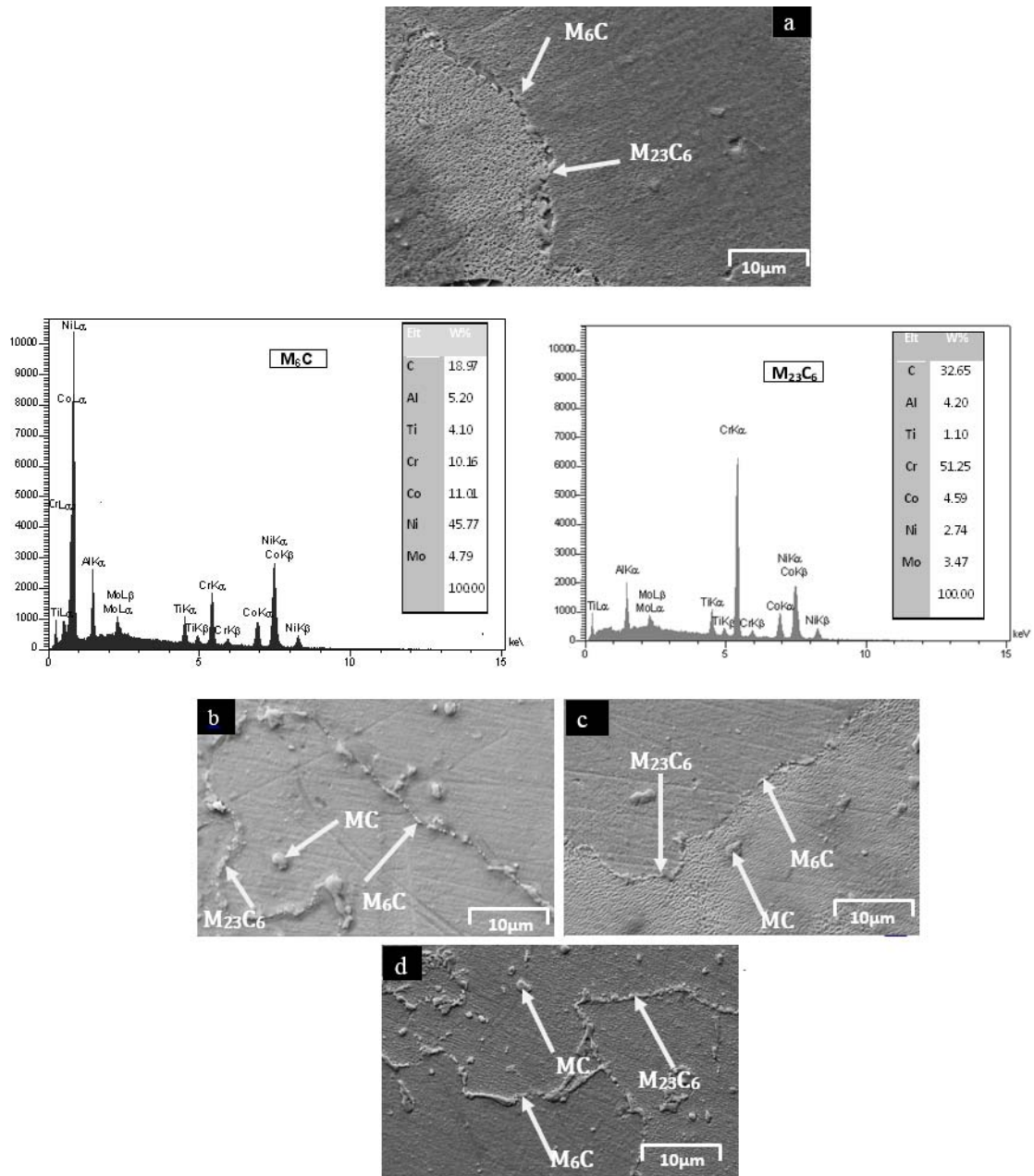

Fig.12. SEM micrographs of carbides after heat treatment according to (a) A; (b) B; (c) $C$ and $(d) D$.

According to the well-known equations (2) and (3), MC carbides are the source of carbon for the formation of other types of carbides in subsequent heat treatments [20]. In addition, during service, $\mathrm{MC}$ carbides may also decompose to other phases such as $\mathrm{M}_{23} \mathrm{C}_{6}$ between $760-980 \mathrm{C}$ and $\mathrm{M}_{6} \mathrm{C}$ between $815-980{ }^{\circ} \mathrm{C}$ temperatures ranges, i.e.:

$\mathrm{MC}+\gamma \rightarrow \mathrm{M}_{23} \mathrm{C}_{6}$ or $\mathrm{M}_{6} \mathrm{C}+\gamma^{\prime}$

$(\mathrm{Ti}, \mathrm{Mo}) \mathrm{C}+(\mathrm{Ni}, \mathrm{Cr}, \mathrm{Al}, \mathrm{Ti})$ from $\gamma \rightarrow$

$$
\mathrm{Cr}_{21} \mathrm{Mo}_{2} \mathrm{Cr} \text { or } \mathrm{Mo}_{3}(\mathrm{Ni}, \mathrm{Co})_{3} \mathrm{C}+\mathrm{Ni}_{3}(\mathrm{Al}, \mathrm{Ti})
$$

As can be seen in Fig. 12 a, the microstructure of the alloy heat treated with A cycle consists of $\mathrm{M}_{23} \mathrm{C}_{6}$ and $\mathrm{M} 6 \mathrm{C}$ carbides. Previous studies [21] indicated that by 
increasing time and temperature of heat treatment, the mentioned transformation progresses rapidly as a result of carbon diffusion acceleration.

Fig. $12 \mathrm{~b}$ shows the morphology of $\mathrm{MC}$ and intergranular $\mathrm{M}_{23} \mathrm{C}_{6}$ and $\mathrm{M}_{6} \mathrm{C}$ carbides of the specimen subjected to the partial solution $\mathrm{B}$ cycle treatment. Due to insufficient time and temperature, the $\mathrm{MC}$ carbide morphology was not changed. One of the purpose of partial solution annealing prior to aging is the formation of discrete $\mathrm{M}_{23} \mathrm{C}_{6}$ and $\mathrm{M}_{6} \mathrm{C}$ carbides within the grains and at the grain boundaries. It is reported [5] that the presence of discrete $\mathrm{M}_{23} \mathrm{C}_{6}$ carbides increases creep rupture life, but reduces the ductility of the alloy.

Fig. $12 \mathrm{c}$ shows the SEM image of the full annealed alloy (C cycle). In this case, the high temperature solution treatment causes more dissolution of carbides into the matrix. This treatment changes the shape of MC carbides from blocky to the spherical one leading to less stress concentration at the interface of $\mathrm{MC} /$ matrix. Besides, in this treatment cycle, EDS analysis revealed that discrete $\mathrm{M}_{23} \mathrm{C}_{6}$ and $\mathrm{M}_{6} \mathrm{C}$ carbides were precipitated only at grain boundaries.

The morphology of carbides by partial+ full annealing treatment (D cycle) is shown in Fig. 12 d. Similar to full annealing, the morphology of the MC carbides was changed to the spherical shape and discrete $\mathrm{M}_{23} \mathrm{C}_{6}$ and $\mathrm{M}_{6} \mathrm{C}$ carbides were precipitated at the grain boundaries, as well. It can be deduced that, by two stage annealing, decomposition of some MC carbides according to equations (1) and (2) leads to change of the morphology of these carbides.

Results showed that partial + full annealed specimen produces the most acceptable microstructure; the primary $\gamma^{\prime}$ phase precipitates in the $\gamma$ matrix with an approximately ordered cubic shape with the highest volume fraction compared to the other heat treated specimens. The alloy undergoing this heat treatment cycle contained $\mathrm{MC}$ carbides with a spherical morphology and grain boundaries decorated with $\mathrm{M}_{23} \mathrm{C}_{6}$ and $\mathrm{M}_{6} \mathrm{C}$ carbides. The as-cast microstructure homogenized and the $\gamma^{\prime} / \gamma$ eutectic volume fraction reached to its minimal value, as well.

\section{Conclusions}

Based on the findings of the current study, the following conclusions are drawn:

1. The microstructure of the as-cast IN100 alloy exhibited the dendritic segregation pattern. The temperature and time of direct aging and partial solution treatment were too low to eliminate the segregation while in full solution and partial+ full solution treatment, it is very hard to distinguish the dendritic segregation pattern. In addition, the volume fraction of $\gamma^{\prime} / \gamma$ eutectic phase was reduced to lower values compared to the as-cast alloy.

2. By direct aging, the shape of the primary $\gamma^{\prime}$ remained unchanged, compared to the as-cast alloy while its size and volume fraction was increased slightly. After partial solution treatment, the primary $\gamma^{\prime}$ morphology was altered by a smaller extent, but did not transform to the ideal ordered cubic shape. In the full solution treated specimens the primary $\gamma^{\prime}$ morphology was changed completely from cubic to spherical.

3. In all heat treated specimens, the morphology of secondary $\gamma^{\prime}$ was spherical and remained unchanged in comparison to the as-cast one. The secondary $\gamma^{\prime}$ 
volume fraction is independent to the heat treatment cycle, while its size was hardly influenced by the heat treatment.

4. As the time and the temperature were insufficient during aging and partial solution treatment, the $\mathrm{MC}$ carbide morphology was not changed. However, some of the $\mathrm{MC}$ carbides were decomposed to $\mathrm{M}_{23} \mathrm{C}_{6}$ and $\mathrm{M}_{6} \mathrm{C}$ within the grains and at the grain boundaries during heat treatment.

The partial+ full annealed specimen produces the optimal microstructure: the primary $\gamma^{\prime}$ phase precipitates in the $\gamma$ matrix with an approximately ordered cubic shape with the volume fraction highest compared to other heat treated specimens. In addition, the alloy undergoing this heat treatment cycle contained $\mathrm{MC}$ carbides with a spherical morphology and grain boundaries decorated with $\mathrm{M}_{23} \mathrm{C}_{6}$ and $\mathrm{M}_{6} \mathrm{C}$ carbides.

\section{References}

[1] R.C. Reed, The Superalloys: Fundamentals and Applications, New York: Cambridge University Press; 2006.

[2] B.H. Doherty, B.J. Piearcey, Acta Met. 239 (1967) 1209-1215.

[3] M. T. Jovanovic, B. Lukic, Z. Miskovic, I. Bobic, I. Cvijovic, B. Dimcic. In: Proceedings Association of Metallurgical Engineers of Serbia 2008, p. 91.

[4] M.T. Jovanovic and S. Tadic, Mat. Char. 30 (1993) 3-12.

[5] W.E.Voice, R.G.Faulkner, Metal. Trans. A. 16 (1985) 511-520.

[6] B. Tang, L. Jiang, R. Hu, Q. Li, Materials Char. 78 (2013) 144-150.

[7] J. Safari, S. Nategh, J. Mate. Proc. Tech. 176 (2006) 240-250.

[8] N. Miura, Y. Kondo, K. Kubushiro, S. Takahashi, Adv. Mat. Res. 278 (2011) 132137.

[9] C. Yang, Y. Xu, H. Nie, X. Xiao, G. Jia, Z. Shen, Mat. Des. 73 (2013) 66-73.

[10] R.J. Mitchell, M. Preuss, S.Tin, M.C. Hardy, Mat. Sci. Eng. A. 473 (2008) 158165.

[11] AMS5397, AES Specification standard metal, 1991.

[12] Heat Treating, Metals Handbook, ASM, vol.4, 1991.

[13] S.S. Hosseini, S. Nategh and A. Ekrami, J. All. Comp. 512 (2012) 340-350.

[14] C. Ai, G. Liu, L. Liu, S. Gong, J. Zhang, H. Fu, Rare Met. Mat. Eng. 41 (2012) $1336-1340$

[15] Wenzhong Jin, Tingju Li, Guomao Yin, Sci. Tech. Adv. Mat. 8 (2007) 1-4.

[16] P. Silva, R. Baldan, C. A. Nunes, G. Coelhoa, A. Costa, Mat. Char. 75 (2013) 214219.

[17] S.A. Sajjadi, S. M. Zebarjad, R.I.L. Guthrie, M. Isac, J. Mat. Proc. Tech. 175 (2006) 376-381.

[18] J. Yu, X. Sun, N. Zhao, T. Jin, H. Guan, Z. Hu, Mat. Sci. Eng. A. 460-461 (2007) 420-427.

[19] M. Heilmaier, U. Leetz, B. Reppich, Mat. Sci. Eng. A. 319-321 (2001) 375-378.

[20] M.J. Donachie, S.J. Donachie, Superalloys a Technical Gudie, 2nd ed., ASM international, 2002.

[21] M.A. Gonzalez, D.I. Martínez, A. Perez, H. Guajardo, A. Garza, Mat. Char. 62 (2011) 1116-1123 